\title{
Efficacy and Safety of Rituximab in Biologic-Naive Patients with Rheumatoid Arthritis vs Anti-Tnf Therapy Failure
}

\author{
Luis Arturo Gutierrez-Gonzalez ${ }^{*}, 1$, Marco Antonio Rivera Gudiño ${ }^{1}$, Ibell Oropeza Ceija ${ }^{2}$, Marialina \\ Marin Leonet ${ }^{1}$ and Zair Tovar Noguera ${ }^{1}$ (GRUPO GRUVEA: Venezuelan Group for the Study of \\ Rheumatoid Arthritis)
}

\author{
${ }^{1}$ Hospital Universitario de Caracas, HUC-UCV, Venezuela \\ ${ }^{2}$ Hospital “Dr. José María Vargas”, Caracas, UCV, Venezuela
}

\begin{abstract}
Objectives: Our aim was to compare an AntiCD20 therapy (rituximab) for rheumatoid arthritis in two patient populations (Group 1), anti-TNF $\alpha$ naïve patients and inadequate responders to Anti-TNF $\alpha$ therapy (Group 2).

Methods: We analyzed the efficacy of the drug Rituximab (RTX) in RA patients who failed methotrexate (MTX) or had a relative or absolute contraindication to receive anti-TNF $\alpha$ therapy.

Results: 25 patients were identified according to the above criteria and followed up for a mean period of 6 months. Thirteen patients were biologic naïve and twelve patients had already failed anti-TNF $\alpha$ therapy. Group 1 used 2> DMARDs (32\% vs 20\%, p<0.005), group 2 had more years of disease progression $(5 \pm 1.89 v s 4.10 \pm 3.92$, $\mathrm{p}<0.001)$. The remission as measured by the DAS28 reached faster in group $1(1.25 \pm 0.12 v s 2.15 \pm 1.64, \mathrm{p}<0,001)$. Severe infections especially by herpes viruses were more frequent in group 2 .

Conclusions: Comparing clinical improvement in both groups the decrease of acute phase reactants and the clinical remission measured by DAS28 was reached in both groups, however it was reached more belatedly in group 2 (at 6 months), this is due to the fact that they have more years of the disease evolution and a higher HAQ.
\end{abstract}

Keywords: Rheumatoid arthritis, synthetic DMARDs, biologic DMARDs.

\section{INTRODUCTION}

Following the discovery of the Rheumatoid Factor (RF) in the decade of the 40's by Waaler and Rose, RA was accepted as a systemic disease capable of developing multiple antibodies directed against the synovial membrane where the B cells had a leading role [1], as it was implicated in the regulation of the immune system, since beyond the production of antibodies, they are antigen presenting cells that interact with other mononuclear cells and contribute directly in the inflammatory channels; however in 1957 a fact was documented suggesting that this fact was not necessarily true, by proving the concurrence of RA with the agammaglobulinemia produced by inactive B lymphocytes in various patients and it was thought that the presence of $B$ cells was not necessary for the development of RA $[2,3]$.

As of the decade of the 60-70's and based upon the predominance of $\mathrm{T}$ lymphocytes (TLP) in the synovia of patients with RA [4], these cells obtained a leading role which was boosted after evidencing that $\mathrm{CD} 4+\mathrm{T}$ cells activated by antigens, stimulate synovial monocytes,

*Address correspondence to this author at the National Center Rheumatic Diseases (CNER), Hospital Universitario de Caracas, Urbanization Los Chaguaramos, City University UCV, Caracas 1020, Venezuela;

Tel: +58212606.7527; Fax: +582126067179;

E-mail: luiskakuro@gmail.com macrophages and fibroblasts in order to produce cytokines IL-1, IL-6 and anti-TNF $\alpha$. Although, the development of arthritis by collagen experimental models in mice depends upon the presence of B cell, since animals deficient of these cells are resistant [5].

The synovial membrane in patients affected by RA is characterized by hyperplasia, increase of vascularity and presence of an infiltration of inflammatory cells, particularly CD4+T cells, which are the principal component of the adaptive immune response. In genetic studies, RA is strongly associated with the presence of class II molecules of the histocompatibility principal complex, especially of the HLADRB1*0404 and DRB1*0401 alleles [6]. The principal function of these molecules is to present antigenic peptides toCD4+T cells, which suggests that RA is caused by arthritogenic antigens which are not yet well identified. These antigens could be exogenous proteins, e.g. viral or endogenous proteins, such as citrullinated proteins, glycoprotein 39 of human cartilage, HSP and union to the heavy chain proteins [7-9].

In spite of the arrival of new biological therapies, particularly Anti-TNF $\alpha$ therapies, a rate of more than $30 \%$ of non-responders is described, moreover having a higher rate of efficacy or tolerance loss having more than 3 years receiving anti-TNF $\alpha[10]$, recommending the use of other molecules such as Anti-CD20, Anti-IL6 or co-stimulation inhibitors (CTLA-4) in case of biological failure; 
notwithstanding the rates of efficacy and remission are very low (ACR $70<35 \%$ ) and the rate of adverse events increases as explained by the years of application and the accumulation of immunosuppressive therapy, for this reason the following study was designed $[11,12]$.

\section{THE OBJECTIVE OF THE STUDY}

Determine the efficacy and safety of the Rituximab antiB cell (AntiCD20) drug in patients with rheumatoid arthritis who have failed therapy with synthetic DMARDs, compared with patients in whom the anti-TNF- biological therapy failed.

\section{PATIENTS AND METHODS}

The type of the study is prospective longitudinal where the selection was done by the aliquot method (patients that consulted a specialized clinic in rheumatology and fulfilled all the selection criteria). 25 patients diagnosed with rheumatoid arthritis were included according to the criteria of the American College of Rheumatology (ACR 1987). The data of patients were submitted to HAQ and DAS28 surveys, visual analogous scale (VAS), also X-ray of hands and feet with fine grain industrial plaque, routine laboratory: Complete blood count, erythrocyte sedimentation rate (ESR), "C" reactive protein (CRP), blood chemistry, urinalysis, immune-rheumatologic profile (ANA, rheumatoid factor, double stranded Anti-DNA, Anti-CCP). Clinical and radiological evaluations were executed at 3 and 6 months after starting the study.

The inclusion criteria were the following patients: 18 years of age or older, with RA according to ACR 1987 criteria, in functional I-II class and in activity with DAS28 $>2.6$ and increased acute phase reactants CRP $<6 \mathrm{mg} / \mathrm{dl}$ or ESR $>20 \mathrm{~mm}$ ). We proceeded to divide them in two (2) groups, the first with inadequate response to treatment with leflunomide and/or MTX one average dose of $20 \mathrm{mg} / \mathrm{d}$ or 15 $\mathrm{mg} /$ week respectively, at least during 12 weeks at a stable dose the last 4 weeks before screening, and the second group with inadequate response to Anti-TNFa therapy during at least 24 weeks of continuous treatment. The use of disease modifying drugs (DMARD) and the concomitant use of glucocorticoids were allowed, a stable dose not higher than $10 \mathrm{mg}$ daily with prednisone or its equivalent, in both groups a dose of 1 gram of rituximab day 1 and at day 15 was applied.

Pregnancy patients, patients with a previous diagnosis of overlap syndrome, SLE and/or mixed connective tissue disease, recent severe infection (< of 1 year), history of malignant neoplasm disease or in remission from it for less than 2 , were excluded.

At the beginning of the study and at month 6, hand and feet X-rays were performed and they were analyzed by the Van der HeijdeSharp modified method. Progression or severity of the disease was defined, if in the radiological control study erosions appeared in patients who did not have them at the beginning, or if there was an increment in the grade of erosion in those who did not have it at the beginning of the study (Fig. 1).

\section{Statistical Analysis}

As patients entered the study, data obtained were stored in a data base contained within the statistical program SPSS Version 10.00. After completing simple recollection we proceeded to perform the quantitative analysis of the data, for which the descriptive analytical methods were applied such as: averages, percentages and standard deviations, rate of prevalence, among others, such as risk association measures with the odds ratio and the exact Fisher test.

\section{RESULTS}

25 patients were included $(n=25)$ with an RA diagnosis who had therapy failure with non-biological DMARD and biological DMARDS, they were distributed into 2 groups, the first with 13 patients with a DMARD failure and who never received biological treatment (Biologics naïve) and the second group with 12 patients who failed the Anti-TNF $\boldsymbol{\alpha}$ therapy (Table 1). The average age was 52.32 \pm 6.09 , more than $90 \%$ were feminine and in average, the disease's duration was higher in the group of the Anti-TNF $\boldsymbol{\alpha}$ failure $(10.04 \pm 3.92)$. $75 \%$ of the patients in group 1 received methotrexate in comparison with $82 \%$ of group 2 , less than $8 \%$ in both groups received leflunomide, $23.4 \%$ of patients received hydroxychloroquine in group 1 and only $9 \%$ in group 2 (Table 1).

Even though in group 1 there were fewer patients with positive rheumatoid factor, they received rituximab (the guidelines recommended or suggested their use only in seropositive patients for RF). The accumulated dose for the glucocorticoids was $3.57 \pm 1.48$ in group 1 while in group 2 it was $7.85 \pm 2.57$.

The 6 months cohort, group 1 had a significant difference in HAQ changes with a $\mathrm{p}<0.001$ and a relative risk of DAS28 2.85, 95\% confidence interval (CI) 2.08 to 3.91 compared with the group 2 (Table 2 ). In the study no antiTNF $\alpha$ antibodies anti chimeric (HACA) were requested, even though 7 patients in group 2 received infliximab, 4 received adalimumab and only 1 patient etanercept.

There was no progression of the disease from the radiological point of view for both groups, and the proportion of patients with changes from the baseline to the cutoff date at 6 months was less than -0.5 and without deterioration of punctuation of the erosion (more than 1 in any joint according to Van der Heijde modified Sharp's Score).

Declines of DAS28 were observed in both groups at 3 and 6 months, even though the greatest decline was observed in the cohort in month 6 in group 1 with a $p<0.001$ in comparison to group 2 (Fig. 2). Similarly, while evaluating $\mathrm{HAQ}$ at 3 and 6 months in group 1 there was a decline below 1.00 (HAQ), maintaining the values above 1.00 (group 2 HAQ 6m) for those who received Anti-TNF therapy previously (Fig. 3).

\section{Adverse Events}

Within the severe adverse events mostly observed was infection by herpes Zoster ( 2 patients), both occurred in 


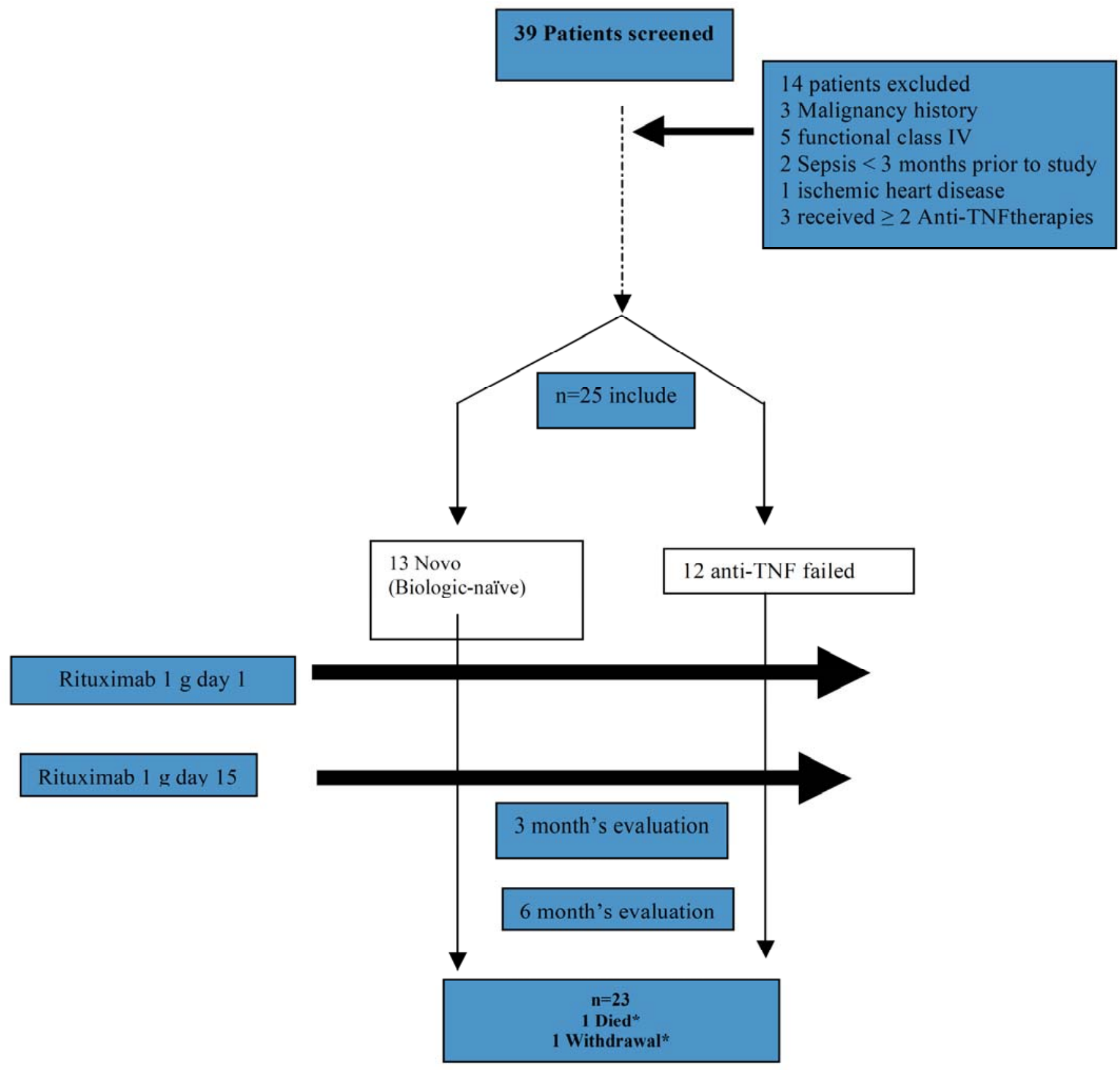

\section{*both were included in the final analysis}

Fig. (1). Enrollment and Outcomes.

patients older than 55 years of age, who had already received 2 DMRDs and Anti-TNF therapy, both were in group 2. Within the most common post transfusion reactions there were 4 flu-like which improved with the use of common antipyretics (acetaminophen), no lupus-like, no modified psoriasis were observed, 2 cases of hematological toxicity were evidenced: one case of bicitopenia and one case of nonfeverous neutropenia, both referred to a hematological specialist which were catalogued as transitory, one allergic reaction (cutaneous toxicity: urticarial) which was resolved with anti-histaminic of $3^{\text {rd }}$ generation (Table 3 ). One patient in group 2 died during a surgical intervention of cholecystectomy, the cause was a heart attack during surgery.

\section{DISCUSSION}

The treatment of rheumatoid arthritis has changed radically in the last decade, the use of the pyramidal treatment for RA already seems as an anachronism, while treatments were initiated in a staggered manner with nonsteroidal anti-inflammatory (NSAIDs), leaving DMARDs as a second option [13,14], which made many patients develop a disabling disease in a short time [15]. Currently, the international guidelines or consensus recommend the use of DMARDs in early RA, and should there be failure to MTX in 3 to 6 months the patients should be transferred to biological therapy with Anti-TNFa, this is due to the fact that in clinical studies in the decade of the 
Table 1. Patients Baseline Characteristics

\begin{tabular}{|c|c|c|c|}
\hline Age $($ Years \pm SD $)$ & $\begin{array}{c}\text { Group 1 } \\
n=13 \\
(\text { Biologic-Naïve) } \\
\mathbf{5 0 . 3 2} \pm \mathbf{4 . 5 7}\end{array}$ & $\begin{array}{c}\text { Group } 2 \\
\mathrm{n}=12 \\
\text { (Anti-TNF } \alpha \text { Failed) } \\
52 \pm 6.09\end{array}$ & $\begin{array}{c}\text { P Value } \\
p=0.08\end{array}$ \\
\hline \multicolumn{4}{|l|}{ Sex } \\
\hline Male & $1(4 \%)$ & $1(4 \%)$ & \\
\hline Female & $12(48 \%)$ & $11(44 \%)$ & \\
\hline \multicolumn{4}{|l|}{ DMARD numbers } \\
\hline One (1) used & $5(20 \%)$ & $7(28 \%)$ & \\
\hline $2 \geq$ more frequently used & $8(32 \%)$ & $5(20 \%)$ & $\mathrm{p}<0.005$ \\
\hline Duration of the disease years $\pm S D$ & $5 \pm 1.89$ & $10.04 \pm 3.92$ & $\mathrm{p}<0.001$ \\
\hline ESR baseline $(\mathrm{M} \pm \mathrm{SD})$ & $47.39 \pm 7.69$ & $35 \pm 5.12$ & $\mathrm{p}<0.001$ \\
\hline CRP baseline mg/dl: $(\mathrm{M} \pm \mathrm{SD})$ & $12.25 \pm 2.68$ & $9 \pm 1.08$ & $\mathrm{p}<0.001$ \\
\hline DAS28 baseline $(\mathrm{M} \pm \mathrm{SD})$ & $4.93 \pm 0.37$ & $3.78 \pm 0.12$ & $\mathrm{p}=0.34$ \\
\hline HAQ baseline: $(\mathrm{M} \pm \mathrm{SD})$ & $2.33 \pm 0,21$ & $2.55 \pm 0.11$ & $\mathrm{p}=0.08$ \\
\hline Rheumatoid Factor positive (\%) & $11(84.6 \%)$ & $12(100 \%)$ & $\mathrm{p}=0.81$ \\
\hline Anti $\mathrm{CCP}$ positive $>25 \mathrm{Ui} / \mathrm{ml}$ & $8(61.5 \%)$ & $9(75 \%)$ & $\mathrm{p}=0.1$ \\
\hline
\end{tabular}

SD: standard deviation. DAS: Disease Activity Score. HAQ: Health Assessment Questionnaire. ESR: erythrocyte sedimentation rate. CPR: "C" reactive protein, RF-Test: Screening Test for Rheumatoid Factor. Anti-CCP: Antibodies against citrullinated peptides. DMARD: disease-modifying anti-rheumatic drugs.

nineties, the chief cytokine or pivot cytokine in rheumatoid arthritis was considered to be the TNFa [16-20], however in recent years other types of anti-cytokines have developed (Anti IL-1, Anti IL-6 y Anti IL-21/23), in response to a group of patients who had failed the anti-TNFa therapy [2126].

We have evaluated the efficacy and safety of rituximab in patients with active RA and with an inadequate response to anti-TNFa therapy. We also compared the use in patients with established rheumatoid arthritis (not early arthritis) and failure to DMARDs, in both cases there was a clinical improvement and the radiographic progression of the disease
Table 2. Changes of Baseline DAS28, HAQ, VSG and CRP at 6 Months

\begin{tabular}{|c|c|c|c|c|c|}
\hline \multirow{2}{*}{} & \multicolumn{2}{|c|}{ Group 1 } & \multicolumn{2}{c|}{ Group 2 } & \multirow{2}{*}{ P Value } \\
\cline { 2 - 5 } & Baseline & $\mathbf{6 ~ m}$ & Baseline & $\mathbf{6 m}$ & \\
\hline \hline ESR mm & $47,39 \pm 7,69$ & $12 \pm 1.23$ & $35 \pm 5.12$ & $15 \pm 2.89$ & 0.081 \\
\hline CRP mg/dl & $12,25 \pm 2,68$ & $4 \pm 0.89$ & $9 \pm 1.08$ & $6 \pm 0.26$ & 0.164 \\
\hline DAS 28 & $4,93 \pm 0,37$ & $1.25 \pm 0.12$ & $3.78 \pm 0.12$ & $2.15 \pm 1.64$ & $<0.001$ \\
\hline HAQ* & $2.33 \pm 0,21$ & $0.758 \pm 0.11$ & $2.55 \pm 0.11$ & $1.18 \pm 0.47$ & $<0.001$ \\
\hline
\end{tabular}

3 , with higher scores indicating greater disease activity.

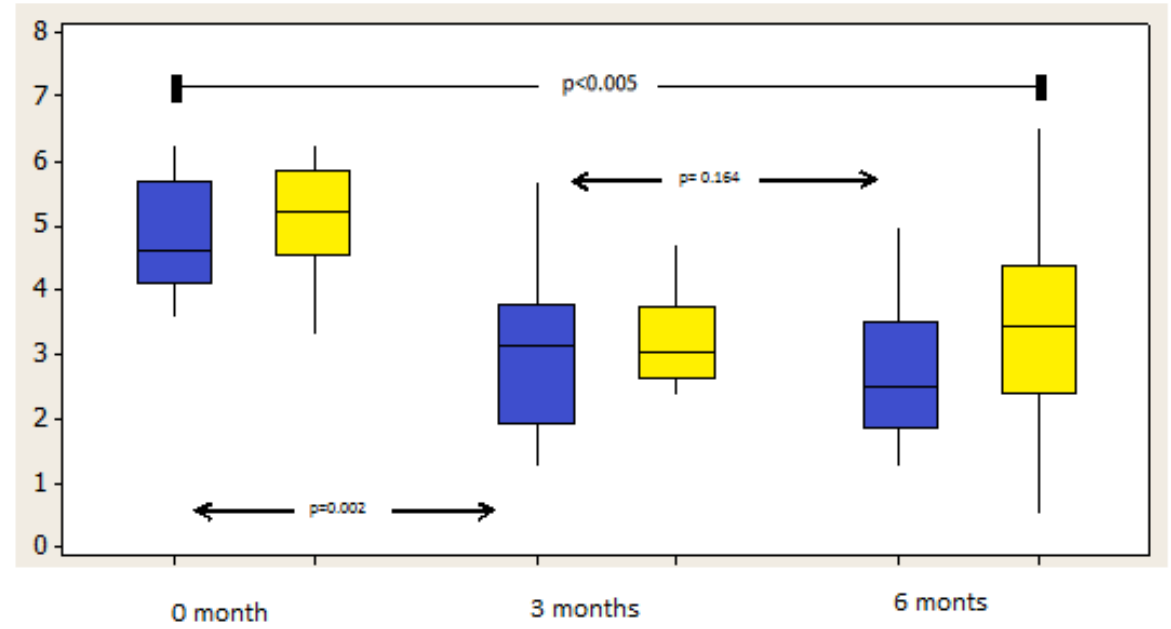

Box blue: Naïve-biologics Box yelow: AntiTNF Failure

Fig. (2). DAS28 score variations at 0,3 andd 6 months. 


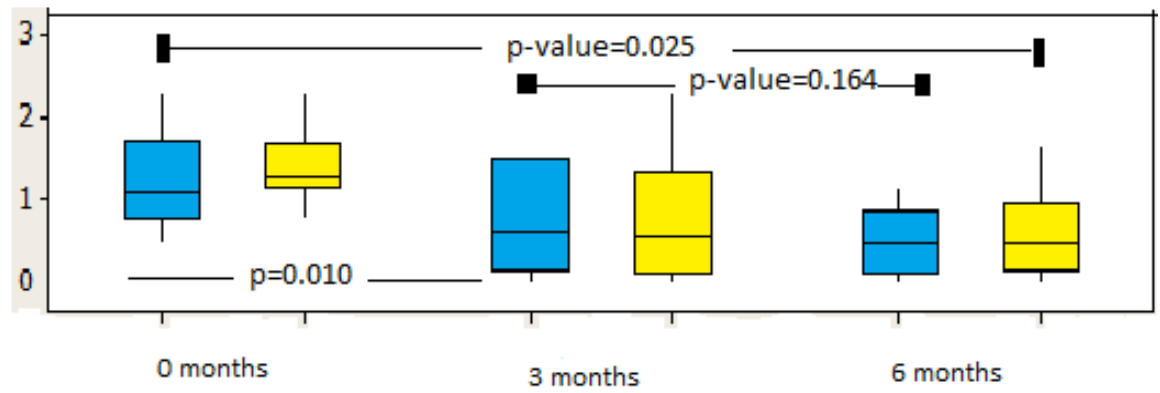

Box blue: Naïvebiologics

Box yelow: Anti-TNF failure

Fig. (3). HAQ score differences at 0, 3 and 6 months.

was avoided, even though a major remission was observed in the group with a lesser progression of the disease, furthermore the HAQ punctuation finalized below 1.00 in group 1, which was reflected in a better functional capability.

Table 3. Adverse Events

\begin{tabular}{|l|c|c|c|}
\hline \multicolumn{1}{|c|}{ Adverse Events } & Group 1 & Group 2 & P Value \\
\hline \hline Deaths & 0 & $1^{*}$ & 1.0 \\
\hline Serious infections & 0 & 2 & \\
Virus Herpes Zoster infection & 0 & 2 & \\
Ramsay Hunt syndrome & 0 & 2 & $<0.001$ \\
Pneumonias & 0 & 1 & 1.0 \\
Acute sinusitis & 1 & 0 & 1.0 \\
\hline Other Adverse Events & & & \\
\hline Flu-Like & 1 & 1 & 1.0 \\
Hematologic toxicity & 1 & 1 & 1.0 \\
Hypersensitivity reaction & 1 & 0 & 0.34 \\
\hline
\end{tabular}

*Patient died during an abdominal chirurgic intervention.

Serious adverse events were more frequent in the group of the anti-TNFa failure, and this is due to the fact that it is a group of patients with older age, with a longer time of disease and with an accumulation of immune suppressor drugs, which make them more susceptible to severe infections.

Comparing clinical improvement in both groups the decrease of acute phase reactants and the clinical remission measured by DAS28 was reached in both groups, however it was reached more belatedly in group 2 (at 6 months), this is due to the fact that they have more years of the disease evolution and a higher HAQ. Perhaps instead of using this drug in patients who failed anti-TNFatherapy, it can be used in patients with early arthritis [27] or simply low dose, for example once a year, to prevent adverse events which have increased as demonstrated by studies Dougados in patients who already had good control or low disease activity [28].

This paper describes a group of patients improved with the use of anti-CD20 therapy, this is a well-known phenomenon, however clinical improvement, adverse events and radiographic progression were better in the group with the lowest time of evolution of the disease and less accumulation of drugs, so you might see use incase synthetic DMARDs fail.

Medical literature describes that there is a failure rate to anti-TNF $\alpha$ therapy ranging from $30-35 \%$, there is even a group of patients who do not respond to methotrexate and who have a relative or absolute contraindication to use Anti$\mathrm{TNF} \alpha$ antagonist as are patients with previous TB infection, malignancy, recent ischemic heart disease or class functional III-IV heart failure [29, 30].

We know that the limitation of the study is the low number of patients, however it is the first study in which we speak of an option(safe and effective) in patients who cannot receive AntiTNF therapy. In our country (and sure in many other), government institutions approved this drug only in RA when AntiTNFatherapy fails.

It is our hope that new tools will be developed that may aid us in choosing the appropriate medication for each type of patient, as for example the creation of a test for immune phenotype or immune chip where we could obtain some information about the type of cellularity or predominant cytokine (cytokine pivot) that is affecting a specific patient $[31,32]$.

\section{AUTHORS' CONTRIBUTIONS}

MM participated in the design of the study and included patients of his daily practice; MR included patients of his daily practice and examined X-ray; IO participated in the design of the study and included patients of her daily practice; ZT participated in the design of the study, performed the statistical analysis and included patients of his daily practice; LAG wrote the manuscript, conceived the study and participated in its design and coordination. All authors read and approved the final manuscript.

\section{ABBREVIATIONS}

$\begin{aligned} \text { MM } & =\text { MarialinaMarín } \\ \text { MR } & =\text { Marco Rivera } \\ \text { ZT } & =\text { Zair Tovar } \\ \text { IO } & =\text { Ibell Oropeza } \\ \text { LAG } & =\text { Luis Arturo Gutiérrez }\end{aligned}$




\section{CONFLICT OF INTEREST}

The authors confirm that this article content has no conflict of interest.

\section{ACKNOWLEDGEMENTS}

Lic. Isabel Moreno Bilancieri.

\section{DISCLOSURE}

Roche Laboratory provides financial support for the radiological and laboratory studies. Biological Drug or synthetic DMARD was provided by the state through IVSS (Instituto Venezolano de los Seguros Sociales), none of the authors received financial support, nor work for Roche or a government enterprise.

\section{REFERENCES}

[1] Waaler E. On the occurrence of a factor in a human serum activating the specific agglutination in sheep blood corpuscles. Acta Pathol Microbial Scand 1940; 17: 172-88.

[2] Eggeland T, Munte E. The role of the laboratory- Rheumatoid factor. Clin Rheum Dis 1983; 9: 135-60.

[3] Reff ME, Carner K, Chambers KS, et al. Depletion of B cells in vivo by a chimeric mouse human monoclonal antibody to CD20. Blood 1994; 83: 435-45.

[4] Gonzalez-Gay MA, Garcia-Porrua C. Hajeer AH. Influence of human leukocyte antigen-DRB1 on the susceptibility and severity of rheumatoid arthritis. Semin Arthritis Rheum 2002; 31(6): 35560.

[5] Nepom GT, Byers P, Seyfield C, et al. HLA genes associated with rheumatoid arthritis: identification of susceptibility alleles using specific oligonucleotide probes. Arthritis Rheum 1989; 32, 15-21.

[6] Weyand CM, Hicok KC, Conn DL, Goronzy JJ. The influence of HLA-DRB1 genes on disease severity in rheumatoid arthritis. Ann Intern Med 1992; 117: 801-3.

[7] Chinh NT, Davis MJ, Tesmer LA, Endres J. Presentation of arthritogenic peptide to antigen-specific $\mathrm{T}$ cells by fibroblast-like synoviocytes. Arthritis Rheum 2007; 56: 1497-506.

[8] Choy EH, Panayi GS. Cytokine pathways and joint inflammation in rheumatoid arthritis. N Engl J Med 2001; 344: 907-16.

[9] Brockhaus M, Schoenfeld HJ, Schlaeger EJ, Hunziker W, Lesslauer W, Loetscher H. Identification of two types of tumor necrosis factor receptors on human cell lines by monoclonal antibodies. Proc Natl Acad Sci USA 1990; 87: 3127-31.

[10] Kremer JM, Westhovens R, Leon M, et al. Treatment of rheumatoid arthritis by selective inhibition of T-cell activation with fusion protein CTLA4Ig. N Engl J Med 2003; 349: 1907-15.

[11] Shanahan JC, Moreland LW, Carter RH. Upcoming biologic agents for the treatmentof rheumatic diseases. Curr Opin Rheumatol 2003; 15: 226-36.

[12] Edwards JC, Szczepanski L, Szechinski J, et al. Efficacy of B-celltargeted therapy with rituximab in patients with rheumatoid arthritis. N Engl J Med 2004; 350: 2572-81.

[13] Cohen SB, Emery P, Greenwald MW, et al. for the REFLEX Trial Group. Rituximab for rheumatoid arthritis refractory to anti-tumor necrosis factor therapy: results of a multicenter, randomized, double-blind, placebo controlled, phase III trial evaluating primary efficacy and safety at twenty-four weeks. Arthritis Rheum 2006; 54: 2793-6.

[14] Moreland LW, O'Dell JR. Glucocorticoids and rheumatoid arthritis: back to the future?. Arthritis Rheum 2002; 46: 2553-63.

[15] Boers M, Verhoeven A, Markusse H, et al. Randomised comparison of combined step-down prednisolone, methotrexate and sulphasalazine with sulphasalazine alone in early rheumatoid arthritis. Lancet 1997; 350: 309-18.

[16] Josef SS, Daniel Aletaha, Johannes WJB, et al. recommendations of an international task force. Ann Rheum Dis 2010 69: 631-7.

[17] Weinblatt M. Rheumatoid Arthritis: Treat now, not later! Ann Intern Med 1996; 124: 773-4.

[18] Möttönen T, Hannonén P, Leirisalo-Repo M, et al. Comparison of combination therapy with single - drug therapy in early rheumatoid arthritis: a randomised trial. Lancet 1999; 353: 1568 -73.

[19] Prevoo ML, van tHof M, Kuper HH, et al. Modified disease activity scores that include twenty-eight joint counts: development and validation. Arthritis Rheum 1995; 38: 44-8.

[20] LoppinE, Garlantezec R, Solau-Gervais E. Low Rate ofRheumatoid Arthritis Remission in Real Life: Might Predictive Factors Explain?. Arthritis Rheum 2010; 62 Suppl10 : 315 .

[21] Jones G, Sebba A, Gu J, et al. Comparison of tocilizumabmonotherapy versus methotrexate monotherapy in patients with moderate to severe rheumatoid arthritis: the AMBITION study. Ann Rheum Dis 2010; 69: 88-96.

[22] Emery P, FurstDE, 1. Ferraccioli G, et al. Long-term efficacy and safety of a repeat treatment course of rituximab in RA patients with an inadequate response to disease- modifying anti-rheumatic drugs. Arthritis Rheum 2006; 54 (Suppl): S228.

[23] Genovese, A Covarrubias, G Leon, et al. Subcutaneous abatecept versus intravenous abatacept: A phase IIIb non-inferiority study in patients with an inadequate response to methotrexate. Arthritis Rheum 2011; 63(10): 2854-64.

[24] Tak PP, Kalden JR. Advances in rheumatology: new targeted therapeutics. Arthritis Res Ther 2011; 25: 13(1 Suppl S5).

[25] Sherrer YS, Bloch DA, Mitchell DM, Roth SH, Wolf F, Fries JF. Disability in rheumatoid arthritis comparison of prognostic factors across three populations. J Rheumatol 1987; 14: 705 - 9.

[26] Jansen LMA, Van der HB IE, Van SD, Bezemer PD, Dijkmans BAC. Predictors of Radiographic joint damage in patients with early rheumatoid arthritis Ann Rheum Dis 2001; 60: 924-7.

[27] Gutierrez-Gonzalez LA, Nuñez-Sotelo CM, Gonzalez N, Losada BR. Early Inflammatory polyarthritis. Rheumatol Curr Res 2012; 2: 109.

[28] Dougados M, Mariette X, Rouanet S, et al. Evaluation of low-dose rituximab for the retreatment of patients with active rheumatoid arthritis: a non-inferiority randomised controlled trial. Ann Rheum Dis 2013 [Epub ahead of print].

[29] Malottki K, Barton P, Tsourapas A, et al. Adalimumab, etanercept, infliximab, rituximab and abatacept for the treatment of rheumatoid arthritis after the failure of a tumour necrosis factor inhibitor: a systematic review and economic evaluation. Health Technol Assess 2011; 15(14): 1-278

[30] Yazici Y. Rheumatoid arthritis: When should we use rituximab to treat RA. Nat Rev Rheumatol 2011; 7(7): 379-80.

[31] Curtis JR, Xie F, Chen L, et al. The comparative risk of serious infections among rheumatoid arthritis patients starting or switching biological agents. Ann Rheum Dis 2011; 70(8): 1401-6.

[32] Strangfeld A, Listing J, Herzer P, et al. Risk of herpes zoster in patients with rheumatoid arthritis treated with anti-TNF-alpha agents. JAMA 2009 18; 301(7): 737-44

(c) Gutierrez-Gonzalez et al.; Licensee Bentham Open.

This is an open access article licensed under the terms of the Creative Commons Attribution Non-Commercial License (http://creativecommons.org/licenses/by-nc/ 3.0/) which permits unrestricted, non-commercial use, distribution and reproduction in any medium, provided the work is properly cited. 